\title{
Esporte, cinema e política na Argentina de Juan Perón (1946-1955)
}

\author{
Victor Andrade de Melo* \\ Maurício Drumond**
}

Resumo: Esse artigo tem por objetivo discutir as relações entre esporte e cinema na Argentina no âmbito do governo de Juan Perón (1946-1955), tendo em conta que uma de suas características foi uma forte ação de propaganda política, que incluía a mobilização de certas manifestações culturais no sentido de difundir valores e comportamentos que interessavam ao ideário que se tentava implementar.

Abstract: This article aims to discuss the connections between sport and cinema in Juan Peron's Argentina (1946-1955), considering that one of its characteristics was a heavy governmental effort in political propaganda, which embraced the mobilization of certain cultural practices as a means of divulging values and behaviors acceptable to the ideology which was meant to be implemented.

Palavras-chave: História do Esporte. Cinema. Argentina.

Key words: Sport History. Cinema. Argentina.

\section{Introdução}

Estudos anteriores já demonstraram as fortes e constantes relações entre esporte e cinema no decorrer da história (Merida, 1995, Ramió, 2003, Marañon, 2005, Baker, 2003, Melo, 2006a), suas articulações no âmbito da constituição do ideário da modernidade (a "invenção da vida moderna", nas palavras de Charney e Schwartz, 2001), bem como as

* Professor do Programa de Pós-Graduação em História Comparada/IFCS/UFRJ. Coordenador do "Sport": Laboratório de História do Esporte e do Lazer<www.sport. ifcs.ufrj.br>; e-mail: victor.a.melo@uol.com.br

** Pesquisador do "Sport": Laboratório de História do Esporte e do Lazer; e-mail: msdrumond@yahoo.com.br 
potencialidades do uso de filmes enquanto fontes históricas que podem contribuir para ampliar nossos olhares acerca da presença social (os sentidos e significados) das mais diversas práticas corporais (esporte, educação física, dança, capoeira, entre outras) (Melo, 2006a).

O relacionamento entre essas duas grandes manifestações culturais do século XX já foi investigado no que se refere a determinadas modalidades esportivas (como nos estudos sobre o boxe, de Merida, 1995, e de Melo e Vaz, 2006; sobre o futebol, de Marañon, 2005, e de Melo, 2006b; e sobre o surfe, de Booth, 2001, e de Melo e Fortes, 2008) e a determinados países (como a Espanha, Ramió, 2003; os Estados Unidos, Baker, 2003; o Brasil, Melo, 2006a; e Portugal, Melo, 2008). Não temos, contudo, estudos mais transversais sobre tal assunto em outros países da América do Sul, ainda que já existam algumas reflexões introdutórias (como, por exemplo, no estudo de Alabarces, 2002).

Parte de uma investigação mais ampla que objetiva analisar a presença da prática esportiva na cinematografia da América do Sul, ${ }^{1}$ esse artigo tem por intuito discutir as relações entre esporte e cinema na Argentina no âmbito do governo de Juan Perón (1946-1955), tendo em conta que uma de suas características foi uma forte ação de propaganda política, que incluía a mobilização de certas manifestações culturais no sentido de difundir valores e comportamentos que interessavam ao ideário que se tentava implementar. ${ }^{2}$

No trabalho de pesquisa realizado sobre a cinematografia de nove países sul-americanos (Argentina, Bolívia, Chile, Colômbia, Equador, Paraguai, Peru, Uruguai, Venezuela), no cinema argentino encontramos 124 filmes onde o esporte de alguma forma foi representado, sendo o primeiro de 1921 (El Triunfo de la Verdad, Rafael Parodi) e o último de 2006 (Puerta 12, de Pablo Tesoriere). Entre as modalidades, encontramse: automobilismo, basquete, esqui, ciclismo, turfe, iatismo, remo, natação, rúgbi, lutas, ginástica e principalmente futebol e boxe, práticas de grande importância para os argentinos. ${ }^{3}$

Vamos nos debruçar sobre uma parte desses filmes, aqueles produzidos em um período de grande importância histórica para aquela nação. Antes, contudo, faremos uma breve análise da importância

1 Essa pesquisa faz parte do projeto "Esporte e Arte: diálogos". Para maiores informações, ver em: www.anima.eefd.ufrj.br/esportearte

2 Para maiores informações, ver estudos de Beretta e colaboradores (1997) e Aringoli (2006).

3 A lista completa e maiores informações sobre os filmes podem ser encontradas em: http://www.anima.eefd.ufrj.br/esportearte/consulta/home.asp 
do esporte no governo de Juan Perón e o seu uso como estratégia de propaganda política do regime.

\section{Perón, esporte e política}

Em abril de 1954, a Avenida Corrientes, uma das principias vias públicas de Buenos Aires, foi palco de um majestoso desfile que envolveu os principais esportistas argentinos, aproximadamente 50 mil atletas das mais variadas modalidades. ${ }^{4}$ Até mesmo o grande astro do automobilismo, Juan Manuel Fangio, participou pilotando sua Ferrari, assim como algumas estrelas do futebol argentino, como Labruna e Loustau, entre tantos. A multidão, formada por jovens e adultos, todos vestindo trajes esportivos, lotou a avenida. O evento contou ainda com discursos de autoridades políticas e exibições de aviões da aeronáutica que formavam com fumaça o nome do presidente nos céus da capital.

O evento fora uma iniciativa da CADCOA(Confederação Argentina de Desportes - Comitê Olímpico Argentino), uma demonstração do reconhecimento e um agradecimento a Perón por suas contribuições para o desenvolvimento do esporte nacional. Em um período no qual já eram sentidas dissidências e seu governo dava sinais de enfraquecimento, o mundo esportivo explicitava seu apoio ao grande líder. Como apontou o jornal Clarin:

No faltó en el desfile ningún deporte. Todos estuvieron dignamente representados, porque todos han recibido de parte del general Perón la ayuda y el estímulo que necesitaban para desarrollarse y alcanzar los legítimos y orgullosos triunfos que nuestra juventud merecía por su esfuerzo, su dedicación y su destreza, triunfo que el pueblo argentino ha celebrado siempre con la íntima satisfacción y el fervor patriótico que tenía derecho a expresar. [...] El polo y el ciclismo, el ajedrez y la natación, el automovilismo y la equitación, el hipismo y el motociclismo, el fútbol y el atletismo en sus diversas ramificaciones, al igual que otras prácticas y ejercicios destinados a vigorar el cuerpo y la mente de la raza. ${ }^{5}$

A Mundo Deportivo, uma revista semanal de forte cunho peronista, dirigida por Carlos Aloé, homem de confiança do presidente, foi ainda mais explícita:

4 Clarín, 22 de abril de 1954, p. 1.

5 Clarín, 22 de abril de 1954, p. 3. 
Nunca, en la rica historia del deporte argentino, que es como decir una de las manifestaciones más puras del pueblo mismo, fué dable presenciar un espectáculo como el que resultó del homenaje al general Juan Perón. Existía en verdad una obligación, no impuesta, sino tácita, para que el torrente que simboliza la actividad deportiva se volcase en las arterias porteñas a fin de brindar ese vibrante grito de '¡Presente!' a quien todo lo da, nada retacea, con el único objetivo de propender a la salud física y espiritual de su pueblo, anhelante de crear una generación jubilosa, sana y virtuosa, que sea capaz de afrontar en las edades venideras la tarea de consolidar la bienaventuranza de la Patria. ${ }^{6}$

A identificação com o esporte e sua importância no âmbito do governo peronista (1946-1955) era tal ordem que o presidente era chamado de "El Primer Deportista", considerado como o ideal do sportsman argentino. Perón, aliás, dizia ter, durante sua juventude, praticado tiro, pólo, natação, futebol, esqui, basquetebol, esgrima e boxe. Efetivamente fora campeão nacional de esgrima de 1918 a 1928, tendo sido inclusive selecionado para competir nos Jogos Olímpicos de 1924 (Paris). ${ }^{7}$ Dizia-se também que fora um bom boxeador amador em sua juventude.

Como se pode ver, até mesmo a imagem pessoal do presidente era muito ligada aos esportes. Não surpreende que, em 1954, a Mundo Deportivo tenha dedicado praticamente uma edição integral ao general. Em um dos artigos, destaca-se a versatilidade e excelência do primeiro mandatário:

Perón conoció a la juventud en los campos de deportes, a los que frecuentó como atleta integral. El boxeador de las clases académicas se transformó en el esgrimista de estilo clásico, y en esa prodigiosa multiplicación de personalidades que forja el estadio, pasó a ser basquetbolista pionero, $\mathrm{y}$ futbolista sagaz, tanto como automovilista fervoroso, capaz motociclista ${ }^{8}$.

Desde o início de seu governo, Perón esteve próximo do esporte. Entretanto, foi mesmo por meio da atuação de sua esposa Eva que alcançou seu maior grau de relação com a prática. Conhecida também como "Evita", "Mãe dos Humildes", "Dama da Esperança", "Fada da Esperança" ou "Chefa Espiritual da Nação", ela assumiu a liderança da

6 Mundo Deportivo, 29 de abril de 1954, p. 4.

7 Perón, contudo, não recebeu autorização do então Ministro da Guerra, Augustín P. Justo, para participar do evento.

8 Mundo Deportivo, 22 de abril de 1954, p. 27. 
ação social no país, em especial após a criação da Fundação Eva Perón, em 1948.

Também conhecida como La Fundación, era administrada pelo Ministro da Fazenda Ramón Cereijo, e apesar de ser, teoricamente, uma entidade não-governamental, estava intimamente ligada ao Partido Justicialista e aos seus principais líderes. Com as ações dessa instituição, Eva alcançou uma grandeza ímpar no regime, tornando-se uma figura quase sagrada, especialmente junto às camadas populares. Sua imagem passou a ser tão importante quanto a do próprio presidente, como se pode perceber no slogan "Perón cumple, Evita dignifica".

Uma das ações da Fundação era organizar, em nome do governo, competições esportivas para crianças, os chamados Campeonatos Infantis Evita, cuja primeira edição foi realizada já em 1948, envolvendo apenas a população da Grande Buenos Aires. Dado o sucesso da iniciativa, esses eventos passaram a ocorrer anualmente, envolvendo várias províncias, já com a denominação de Campeonato Argentino de Futebol Infantil Evita. Nas primeiras etapas os times jogavam nas suas regiões; na fase final, os vencedores se enfrentavam na capital federal, em estádios de equipes profissionais, como os do River Plate, do Boca Juniors e do San Lorenzo, sempre contando com a presença do primeiro casal do país, além de outros políticos da alta esfera do governo.

Esses campeonatos recebiam grande atenção da mídia peronista: além da associação do regime com pratica esportiva infantil, buscava-se enaltecer um sentimento de identificação e integração nacional. A revista Mundo Infantil expressamente entendia que:

O Campeonato Evita irá realizar o sonho de professores e líderes: ele irá unir a juventude argentina através de um laço que transcenderá divisões locais, e mesmo provinciais, porque a voz do esporte é gritante, poderosa, revigorante e eletrificante. Neste quadro, todos se sentirão como iguais, todos pensarão da mesma maneira (apud Rein, 1998, p.59).

A popularidade era assombrosa. A primeira edição contou com mais de 15 mil participantes. No ano seguinte, a imprensa peronista já alardeava que o número de inscritos ultrapassara os 150 mil; o número crescia à medida que mais províncias tomavam parte. Em 1953 foram instituídos os Jogos Esportivos Juvenis Juan Perón e o número de envolvidos excedeu os 200 mil.

Juntamente com a exaltação de nacionalismo, as competições publicizavam a imagem dos governantes. Entre as equipes envolvidas, não era incomum que algumas possuíssem nomes que faziam referência 
ao peronismo, como "17 de Outubro" e "Evita, Estrela da Manhã". Antes dos jogos, os participantes cantavam as marchas "Evita Capitana" e "Los Muchachos Peronistas", além da canção oficial do campeonato: "A Evita devemos nosso clube, por isso lhe guardamos nossa gratidão. Nós cumprimos os ideais, nós cumprimos a Missão, da Nova Argentina de Evita e Perón" (apud Rein, 1998, p.64).

Os Campeonatos Infantis Evita não se resumiram ao futebol. Logo outras modalidades esportivas passaram a ser disputadas, como basquete, atletismo e pólo aquático. Em cada uma das finais, Perón e sua esposa eram presenças garantidas, seja dando o pontapé inicial, distribuindo medalhas ou posando para fotos que seriam publicadas nos mais diversos jornais argentinos no dia seguinte.

Nesse contexto não surpreende que várias praças esportivas tenham sido batizadas em homenagem ao casal presidencial. Em setembro de 1950, o Racing inaugurou o Estádio Presidente Perón, construído com verbas do governo. Já o Club Atlético Sarmiento, em julho de 1951, inaugurou o Estádio Eva Perón. Devemos lembrar ainda do velódromo Presidente Perón, em Palermo, e do autódromo 17 de outubro, em Buenos Aires. Foi bastante comum também a denominação de campeonatos e troféus com nomes de associados ao movimento justicialista.

A Argentina peronista foi ainda sede de diversas competições esportivas internacionais, sendo a mais importante os primeiros Jogos Pan-Americanos, realizados em Buenos Aires, no ano de 1951. A abertura ocorreu no recém inaugurado Estádio Presidente Perón, uma das marcas da tão alardeada benfeitoria governamental ao esporte, e o encerramento no estádio do River Plate, no bairro de Nuñez; essas cerimônias foram obviamente muito exploradas pela máquina de propaganda política. Durante o evento, Perón parecia onipresente, assistindo provas de praticamente todas as modalidades e às disputas de medalhas mais importantes; suas fotos nessas ocasiões foram constantemente publicadas nas páginas dos jornais.

Ao final, a Argentina figurava no primeiro lugar do quadro de medalhas, com 68 de ouro e 150 no total, fato que não passou despercebido: foram alardeadas as virtudes do esporte argentino sob a tutela de Perón, marcadas inclusive pela inquestionável superioridade

9 Em 17 de outubro de 1945, milhares de pessoas se reuniram na Plaza de Mayo para pedir a libertação do então coronel Perón, que havia sido preso por um grupo de militares. Perón foi solto no mesmo dia e discursou à multidão do balcão central da Casa Rosada, de onde anunciou que concorreria às eleições de fevereiro de 1946, quando se tornou presidente argentino. 
sobre as outras nações, em especial sobre os até então imbatíveis Estados Unidos, que ficaram em $2^{\circ}$ lugar. Os Jogos foram encarados como a confirmação pública do sucesso da política esportiva peronista.

Outro destaque foi o Campeonato Mundial de Basquete, realizado também em Buenos Aires, no ano de 1950, no qual o selecionado argentino sagrou-se campeão mundial, derrotando os Estados Unidos no jogo final. Mesmo que o time americano fosse formado por atletas de uma equipe de segunda divisão, o Denver Chevrolet, a vitória argentina foi comemorada profusamente.

Devemos ainda citar o Grande Prêmio da Argentina de Fórmula 1, realizado pela primeira vez em 1953, para o qual foi inclusive construído o autódromo 17 de Outubro. Nesse período, Juan Manuel Fangio se destacava no cenário internacional e se tornou um dos maiores ídolos esportivos argentinos, presença constante nas páginas dos jornais, não poucas vezes ao lado de Perón e Evita. ${ }^{10}$

O boxe também era um esporte muito popular e diversas lutas internacionais foram disputadas no Luna Park, principal arena portenha. O governo peronista não poupou esforços para alçar o pugilismo nacional a uma condição de destaque. Já no Pan-Americano de 1951, boxeurs argentinos alcançaram a medalha de ouro nas oito modalidades disputadas. O título mundial viria em 1954, com Pascual Pérez, também conhecido por Pascualito, na categoria peso mosca. Suas primeiras palavras, logo após a conquista, teriam sido: "Gané para Perón, para mi Patria y para la Argentina" (apud Lupo, 2004, p.314).

Curiosamente o futebol argentino não esteve presente em muitas competições internacionais. Uma greve dos jogadores profissionais, em 1948, desencadeou um êxodo de estrelas para a Colômbia; ${ }^{11}$ como desdobramento, a seleção argentina não participou do campeonato SulAmericano de 1949 e da Copa do Mundo de 1950.

A volta a disputas internacionais ocorreu em 1951, com uma excursão pela Europa: uma derrota para a Inglaterra (2 a 1) e uma vitória

${ }^{10}$ Fangio fora vice-campeão em 1950, o primeiro ano da modalidade, e campeão em 1951 e entre 1954 e 1957, os três primeiros títulos foram conquistados sob o regime peronista.

11 Nessa época, a Colômbia não era filiada à FIFA. Por isso, seus clubes não se viam na obrigação de respeitar contratos e passes que vigoravam no futebol mundial. Os clubes colombianos passaram então a pagar somas astronômicas aos maiores craques da América do Sul, e até mesmo alguns da Europa, que abandonavam suas equipes em meio a seu contrato e se aventuravam no chamado El Dorado colombiano. O caso mais famoso foi o do clube Millonarios, que formou uma verdadeira seleção, encabeçada por um dos maiores jogadores de todos os tempos, o argentino Alfredo Di Stéfano. 
sobre a Irlanda ( 1 a 0 ). Dois anos mais tarde, os ingleses foram à Argentina disputar duas partidas. Os argentinos venceram o primeiro jogo por 3 a 1. O segundo certame, realizado três dias depois, foi cancelado aos 23 minutos do primeiro tempo devido à chuva torrencial. A primeira vitória foi suficiente para a imprensa local exaltar o "estilo criollo", criativo e artístico, contra o estilo frio e mecânico, mas eficiente, dos ingleses:

Una victoria cabal, justa, amplia, histórica, que podría resumirse [...] en la fisonomía de los primeros goles: mecánica fría pero oportuna y exacta, en los ingleses; inspiración casi artística, agudeza de criterio, sublimación de la obra colectiva, de los argentinos (apud Digiano, 1999, s.p.).

A imprensa peronista procurava realçar, pelo exemplo do esporte, a característica de um novo povo. A prática esportiva representaria a pátria; as batalhas travadas nos campos esportivos simbolicamente envolviam toda a nação; as vitórias expressavam as virtudes nacionais, o sucesso era visto como reflexo do progresso do país. Até mesmo as derrotas, quando resultantes de um embate digno ou consideradas como injustas, eram percalços que aproximavam ainda mais o povo de seu símbolo pátrio, de sua seleção, de sua nação.

Uma idéia recorrente nos periódicos ligados ao governo é que a "Nova Argentina", proposta por Perón, tinha o esporte como peça fundamental para a preparação de um novo povo, forte e viril, pronto para vencer:

En la Nueva Argentina la práctica del deporte por la juventud es ensueño cumplido de grandes realidades, donde los hombres aprenden a ser ejemplo de virtudes $y$, sobre todas las cosas, a formar una conciencia colectiva de que todos debemos emplear las fuerzas que la naturaleza nos ha dado y que los hombres han perfeccionado en beneficio de la Nación ${ }^{12}$.

Assim, não se deve negligenciar os impactos desses constructos sobre as representações de masculinidade, algo que recuperava de forma idealizada o passado gaucho da Argentina (amante de sua terra, independente, decidido), estabelecendo uma relação entre virilidade e nação, uma dimensão para o qual a esporte foi muito mobilizado:

En la época del peronismo clásico - aunque ya había marcas fuertes en el gobierno de Manuel Fresco y sobre todo luego del 4 de junio de 1943 - el deporte y el criollismo recibieron vigorosos significados

${ }^{12}$ Mundo Deportivo, 8 de setembro de 1955, p. 26. 
de eficacia política. Pero fue en el campo del deporte donde el cruce entre la "ideología" del gobierno y el partido de Juan y Eva Perón se amalgamaron más hondamente con activos sentimientos populares (Acha, 2002, s.p.).

Enfim, Perón utilizou os elementos esportivos nos mais diferentes sentidos, inclusive buscando tornar os grandes ídolos e as vitórias por eles conquistadas em símbolos da Nova Argentina. A popularidade do esporte era instrumentalizada. Mas isso não se observava somente com a prática esportiva. Outras manifestações culturais também foram utilizadas pela máquina de propaganda montada pelo regime. Entre essas, o cinema.

\section{Perón, o cinema e o esporte}

Desde o início da Segunda Grande Guerra, a indústria cinematográfica argentina passou a enfrentar problemas diversos, em função da redução de mercados internacionais (conseqüência tanto do conflito em si quanto de controversas opções empresariais internas) e do boicote norte-americano ao país, por sua posição de neutralidade na guerra, o que significou a escassez e/ou o encarecimento do material técnico necessário à produção de filmes. ${ }^{13}$

Durante o governo de Perón, o cinema argentino recebeu grande incentivo e passou por um processo de recuperação. Devemos lembrar que, além das motivações políticas, Evita possuía uma profunda ligação com a sétima arte. Ela, que chegara a Buenos Aires com 15 anos, para tentar o futuro como atriz, começou sua carreira em pequenos papéis no teatro e em 1937 debutou no filme ;Segundos Afuera! (Chas de Cruz e Alberto Etchebehere). Atuou ainda em mais cinco filmes até a chegada de Perón ao poder, em 1946.

$\mathrm{O}$ aumento do investimento possibilitou o lançamento de 56 longas em 1950 e de 53 em 1951 (Luna, 2000). Por trás desse estímulo certamente encontravam-se os projetos peronistas:

Uno de los resortes importantes en los que Apold y el peronismo apoyaron su campaña propagandística fue el cine. Pese a que el cine comercial no tiene demasiadas referencias explicitas al peronismo, se produjeron decenas de cortos cinematográficos de propaganda política que se exhibían en salas de cine y los diversos noticieros cinematográficos siendo parte esencial de las campañas de peronismo (Jakubowicz, Radetich, 2006, p.88).

13 Para maiores informações, ver estudo de Maranghello (2005). 
Ainda que os autores acima tenham razão quando afirmam que não houve demasiadas referências explícitas ao peronismo, não devemos negligenciar tal presença nos filmes comerciais, tanto porque o Estado tornou-se um dos maiores investidores da indústria cinematográfica quanto porque o próprio ambiente cultural e político também envolvia muito cineastas. No que se refere às películas em que o esporte esteve presente, que serão mais à frente discutidas, percebe-se ainda mais forte o que afirma Maranghello (2005):

Sin referencias explicitas, muchas películas también expresaban la visión que sostenía el peronismo, en el cruce de dos ejes: la conciliación de los conflictos sociales y la existencia de un Estado fuerte. En contrapartida con la ausencia de apologías directas, se encuentran pocos rastros de crítica política o de aspectos crudos de la realidad (p.114).

Na verdade, havia uma compreensão de que através dos filmes poder-se-ia educar o cidadão argentino dentro dos ideais justicialistas, legitimando e reforçando os laços de identidade do povo com o peronismo.

Há ainda outro elemento que merece atenção: a importância que o esporte, notadamente o futebol, e o cinema foram ocupando como opções de diversão para a população, especialmente na capital:

El fútbol y el cine se han convertido en las diversiones preferidas del porteño. Los cines se van abriendo en los barrios, y los clubes han salido definitivamente del potrero. Los tablones ya van siendo mal mirados por los clubes más ricos que van siendo tentados por el cemento (Bayer, 1990, s.p.).

Não surpreende, assim, que haja tantas confluências entre cinema e esporte durante o regime peronista. Durante os dez anos dos dois primeiros mandatos de Perón (1946 a 1955), foram produzidos 19 longas-metragens cujo tema central era a prática esportiva. Entre as modalidades presentes nas telas, pode-se identificar uma leve predominância do futebol (oito) e do boxe (cinco); outro destaque é o automobilismo, assunto de três filmes.

Um dos destaques desse período foi Pelota de trapo (Leopoldo Torres Rios, 1948), que tem um tema recorrente na cinematografia esportiva mundial: desafortunados que, desafiando a tudo e a todos, chegam ao sucesso através do esporte. O filme narra a história de um jovem, filho de trabalhadores pobres, que quando criança jogava futebol com uma bola feita de trapos e, já adulto, chega ao estrelato; lamentavelmente, uma doença acaba por afastá-lo do sucesso. 
O roteiro é de Ricardo Lorenzo, conhecido como Borocotó, célebre cronista esportivo da revista El Gráfico. Diversos nomes ligados ao futebol aparecem na película: Guilhermo Stábile, então treinador da seleção argentina, Tucho Méndez, José Batagliero, Raúl Bravo, entre vários outros jogadores profissionais. Deve-se ainda destacar a companhia produtora: SIFA, do ator Armando Bó, uma tentativa de implementar na Argentina uma produção fílmica mais freqüente.

Pelota de trapo incorpora o ideal de construção de uma nova "raça argentina". Supostamente, através dos esportes a juventude se fortaleceria e obteria o vigor necessário para ultrapassar quaisquer obstáculos e atingir a glória. Esse era um dos principais motes utilizados pelo Estado peronista em sua relação com a prática esportiva: aí estaria uma de suas grandes contribuições para uma Nova Argentina altiva e soberana. Na verdade, fazia-se eco a uma compreensão que, segundo Archetti (2001), já era corrente desde a década de 1920:

la importancia de los deportes de equipo ya que permiten que una nación se exprese, que sus integrantes tengan una 'conciencia nacional' y superen las identidades locales de clubes o provincias, y porque hacen posible que las diferencias de estilo, en competencia con otros equipos, puedan ser pensadas como manifestaciones de 'estilos nacionales' (p.13).

O comentário de Manrupe e Portela (1995) bem resume a importância dessa película:

Hoy envejecido y plagado de pintoresquismos, fue en su momento un aporte renovador dentro de un panorama acartonado y fuera de la realidad. El rodaje en exteriores, los chicos, el argumento, y un tratamiento sincero y dinámico (sobre todo en la primera parte) hicieron de un film de bajo presupuesto un éxito, el resurgimiento de Torres Ríos, la mejor película de Armando Bó-actor y finalmente, un clásico (p.455).

Também escrito por Borocotó, Con los Mismos Colores (Carlos Torres de Rio, 1949) tinha tema muito semelhante (jovens que lutam para triunfar no esporte), contando com três grandes jogadores no elenco: Alfredo Di Stéfano, então jogador do River Plate, Tucho Méndez, do Racing, e Mario Boyé, do Boca Juniors. Vale lembrar que a película, lançada em setembro de 1949, fora filmada após a grande greve do futebol argentino de 1948. Os torcedores argentinos não voltariam mais a ver Di Stéfano atuar em clubes argentinos. Depois de uma passagem pela Colômbia, ele iria para a Espanha onde se tornaria ídolo e atuaria nos filmes Saeta Rubia (Javier Setó, 1956) e La Batalla del Domingo (Eduardo Mesquita, 1963). 
A música de Astor Piazola que percorre a trama não é ocasional. Como lembra Archetti (2001), no processo de construção de identidade argentina: "La asociación entre fútbol y tango será más obvia que en el caso del boxeo o el automovilismo" (p.17). O mesmo autor lembra que Borocotó, em 1928, já afirmava que futebol e tango eram expressões típicas argentinas, reconhecidas e admiradas por todo o mundo.

Uma relação ainda mais explícita com as idéias do governo Perón pode ser encontrada em Sacachispas (Jerry Gomez, 1950), último filme escrito por Borocotó. Trata-se de uma história sobre um time de meninos criado por um jornalista (interpretado pelo próprio cronista) no bairro de Villa Soldati, em Buenos Aires. A equipe foi criada em 17 de outubro de 1948, data simbólica do peronismo, e competia nos Campeonatos de Futebol Infantil Evita; o terreno de seu primeiro campo de treinamento foi cedido ao clube pelo presidente: propaganda mais explícita, impossível.

Já Escuela de Campeones, também de 1950, dirigido por Ralph Pappier, conta a história de Alejandro Watson Hutton, um dos introdutores do futebol na Argentina. Hutton foi um escocês que chegou a Buenos Aires, na década de 1880, para trabalhar como professor na escola Saint Andrew. Ele viria mais tarde a criar a Buenos Aires English High School, escola ligada ao time Alumni, o maior vencedor do futebol argentino nos tempos de amadorismo.

Outro filme que narra uma história ligada ao velho esporte bretão, na mesma medida em que reforça a idéia de que o futebol pode ser utilizado como fator de mobilização e envolvimento juvenil, é El Cura Lorenzo (1954), dirigido por Augusto Vatteone. O tema da película é, na verdade, a vida do padre Lorenzo Mazza, que, desafiando dificuldades e hostilidades, funda o Club San Lorenzo de Almagro como forma de apresentar uma alternativa para os jovens.

A torcida é o tema de dois filmes desse período, El Hincha (Manuel Romero, 1951) e El Hijo del Crack (Leopoldo Torres Rios, 1953). O primeiro, uma comédia, narra a paixão de um torcedor, já captando o enorme envolvimento dos argentinos com o velho esporte bretão. $\mathrm{O}$ segundo é mais um filme produzido pela SIFA, com a participação de Armando Bó como ator, e recupera o velho drama do jogador que enfrenta percalços, nesse caso com a torcida que lhe persegue, mais ao fim triunfa graças a seu empenho. ${ }^{14}$

14 Há ainda outro filme em que o futebol esteve centralmente presente: Cinco grandes y una chica (Augusto Vatteone, 1950), com a participação do famoso grupo Los Cinco Grandes del Buen Humor, já famoso no rádio e que começara a se aventurar nas telas de cinema no final da década de 1940. É uma crítica cômica às diversas falcatruas que podem cercar o esporte. 
O boxe, outro esporte bastante presente nos filmes do período, já gozava de grande popularidade na Argentina desde o início do século, algo que se tornou denotado depois do sucesso internacional de Luis Angel Firpo. A vida desse boxeador, que inclusive no filme interpreta o papel de um promotor de lutas, é o tema central de Nace un Campeón (Roberto Ratti, 1952).

Da mesma forma, Su Última Pelea (Jerry Gomez, 1949) é baseado na história de Justo Suárez, também conhecido como "El torito de Mataderos", apontado por Archetti (2001) como o primeiro boxeador argentino a atrair as multidões. Suárez obteve grande sucesso até sua segunda excursão pelos Estados Unidos, quando foi pela primeira vez derrotado, por Billy Petrolle, possivelmente já um sinal da tuberculose que acabou tirando sua vida em 1938, aos 29 anos. Sua vida acabou sendo o mote perfeito para o roteiro de Borocotó, que na verdade praticamente repete o enredo de Pelota de Trapo: um garoto nascido em um bairro pobre de Buenos Aires se transforma em um boxeador de grande sucesso, mas a tuberculose e um crime passional acabam com sua carreira.

$\mathrm{Na}$ verdade, a vida dos boxeadores tem grande relação com a construção identitária argentina, pela idéia de superação, pela construção de modelos de masculinidade, ${ }^{15}$ pela questão da mobilidade social, bastante marcante em um país cuja capital tinha uma população formada por muitos imigrantes; e mesmo pelos constantes apoios governamentais ao esporte.

Não surpreende que futuramente outros filmes viessem a tratar da mesma temática, com destaque para Los Golpes Bajos (Mario Sabatto, 1974) e Gatica “El Mono” (Leonardo Favio, 1993), ambos fazendo uma conexão direta entre o peronismo e a trajetória do boxeador José Maria Gatica. Como lembra Archetti (2001): "Su biografía nos confronta con tres ejes importantes. El primero, su identificación política visceral con el peronismo y su devoción confesada por el Presidente Perón y Evita Perón, recíproca, por lo menos hasta 1951" (p.104). Ao mesmo tempo, as suas lutas faziam emergir as diferenças políticas do cenário argentino:

Se decía que, en sus peleas en el Luna Park, los espectadores de la tribuna popular iban a verlo ganar y los del ring-side, supuestamente antiperonistas, perder. Gatica tenia la virtud de hacer visibles las divisiones políticas que existían en el país. El boxeo era política y, mejor aún, política simbólica (Archetti, 2001, p.104).

15 Para maiores informações, ver estudo de Archetti (2003). 
A idéia de superação e mobilidade social pode ser vista uma vez mais em Diez Segundos (Alejandro Wehner, 1949): um garoto franzino aprende a lutar boxe como um meio de defesa pessoal e acaba por se tornar em um pugilista profissional. Novamente vemos o esporte representado como uma importante ferramenta de formação física e mental do jovem protagonista. O outrora fraco que adere à prática esportiva por uma necessidade concreta acaba, por tal envolvimento, transformando-se em um grande homem, independente e vitorioso. Era isso que se esperava da nação. Ao educar as crianças através do esporte, se estaria contribuindo para o futuro promissor da pátria.

Esse tema ganha uma leve cor diferente em Campeón a la Fuerza (Juan Sires, 1950). Além do tom de comédia, em que se destaca o ator Castrito, entre muitos personagens conhecidos do rádio e do cinema da época, o personagem central, explorado e ameaçado por um inescrupuloso empresário, tornando-se atleta não só de boxe, como de natação e atletismo. Ao final, uma grande virada o redime e o liberta.

O automobilismo, que a Argentina da época passou a muito apreciar, em grande parte graças ao sucesso de Juan Manuel Fangio, também foi tema de filmes, entre os quais um roteirizado por Borocotó: Bólidos de Acero (Carlos Torres Rios, 1950), um drama musical com trilha sonora de Astor Piazzolla, a história de superação de um rapaz humilde na sua tentativa de se tornar um grande piloto campeão. Interessante observar que uma vez mais o esporte e o cinema articulavam-se com outro importante símbolo da identidade argentina: o tango. Da mesma forma, como se pode ver, o enredo é muito similar a algumas produções do período.

Do mesmo ano é Fangio, el Demônio de las Pistas (Roman Viñoly Barreto, 1950), um drama/documentário que reproduz momentos marcantes da história do automobilista, já um grande ídolo antes mesmo da conquista de seu primeiro campeonato mundial.

Deve-se destacar que, até mesmo em função da popularidade e dos sentidos e significados do automobilismo, signo de progresso, o regime peronista dele também se aproximaria: "Perón defendió el significado de la carretera porque mostraba el coraje de los pilotos argentinos, porque ayudaba a 'conformar un espíritu nacional que cada día se aglutina más" (Archetti, 2001, p. 82).

Os investimentos governamentais, assim, foram intensos e ampliaram as possibilidades de vitória de Fangio, logo reconhecido como um gênio do volante. Isso servia a dois intuitos: 
El ACA [Automóvil Club Argentino] y el gobierno argentino veían en esos triunfos la posibilidad de ubicar a la Argentina, al menos, en condiciones de igualdad con las naciones modernas industriales. La Argentina participo de un modo privilegiado en la consolidación de un espacio global de competencias automovilistas y Fangio fue, sin duda alguna, el símbolo de una nación. [al mismo tempo] La Argentina había encontrado un héroe que no solo expresaba ideales de movilidad social, igualdad de oportunidades e integración social, sino que era, además, capaz de vencer a los mejores pilotos europeos en las carreras de pista (Archetti, 2001, p.88).

Há mais três filmes que merecem destaque pela sua adequação ao espírito do tempo. Um dos mais ligados ao ideário do regime foi o documentário Batalla de Campeones (Juventud de las Americas en la Nueva Argentina). A película tem como tema os jogos Pan-Americanos de 1951, ligando abertamente a imagem de Perón ao sucesso esportivo. A idéia de uma Nova Argentina peronista aparecia estampada no próprio título da película.

En Cuerpo y Alma (1953), de Leopoldo Torres Rios, aproveita o momento de grande popularidade do basquetebol, conseqüência dos bons resultados obtidos pela equipe argentina em competições internacionais. $\mathrm{Na}$ trama, dois jovens, que demonstram talento para o esporte, disputam o amor de uma mulher. Curioso é o que informava o cartaz do filme: "El más viril de los deportes y el más humano y tierno de los romances, en una película sencillamente humana. La emoción del básquetbol pero con sus ases más prestigiosos por primera vez en la pantalla" (apud Manrupe, Portela, 1995, p.200).

Por fim, Canción de la Nieve (Guzzi Lantscher, 1954) narra a disputa de um campeonato de esqui na região de Bariloche. Na verdade, o filme é praticamente um documentário dedicado a exaltar as belezas da "grande nação Argentina". Curiosamente os papéis principais foram representados, com deficiência, pelos próprios atletas; o diretor fora câmera de Leni Riefenstahl, possuindo experiência em captar imagens de montanha.

\section{À guisa de conclusão}

O governo de Juan Perón (1946-1995) foi, em grande medida, marcado por sua liderança carismática, maleabilidade ideológica e distanciamento da idéia de democracia liberal. Nesse contexto, entendiase a intervenção cultural como um suporte para a política, uma estratégia de mobilização e formação das massas (Surra, 2003). 
Nesse sentido, buscava-se mobilizar a imagem dos ídolos esportivos e cinematográficos, suas vitórias e desempenhos, como símbolos de uma "Nova Argentina". Reunindo os espectadores em torno de ícones que fossem capazes de representar uma nova nação, apresentava-se a idéia de uma nova sociedade, que objetiva-se construir e consolidar sob uma imagem harmônica e homogênea.

Esporte e cinema ocuparam, portanto, uma função mediadora: com o compartilhamento de símbolos em comum, a população se sentiria parte de uma mesma comunidade imaginada (Anderson, 2005). Foram instrumentos utilizados com o intuito de criar representações coletivas adequadas ao imaginário propugnado pelo regime e sua concepção de um novo modelo de nação.

\section{Referências}

ACHA, Omar. El hincha y el futbolista: masculinidad y deseo homosexual en el cine durante la década peronista (Argentina, 1946-1955). Lecturas: Educación Fisica y Deportes, Buenos Aires, ano 8, n. 55, s.p., dez. 2002.

ALABARCES, Pablo. Fútbol y patria: el fútbol y las narrativas de la nación en la Argentina. Buenos Aires: Prometeo Libros, 2002.

ANDERSON, Benedict. Comunidades Imaginadas: reflexões sobre a origem e expansão do nacionalismo. Lisboa: Edições 70, 2005.

ARCHETTI, Eduardo P. El potrero, la pista y el ring: las patrias del deporte argentino. Buenos Aires: Fondo de Cultura Económica, 2001.

ARCHETTI, Eduardo P. Masculinidades: fútbol, tango y pólo en La Argentina. Buenos Aires: Antropofagia, 2003.

ARINGOLI, Guilhermo D'Arino. La propaganda peronista: 1943-1955. Ituzaingó: Maipue, 2006.

BAKER, Aaron. Contesting identities: sports in American Film. Chicago: University of Illinois Press, 2003.

BAYER, Osvaldo. Agnósticos y creyentes, proletarios y bacanes. Lecturas: Educación Fisica y Deportes, Buenos Aires, n. 10, s.p., 1990,

BERETTA, Alcides et al. Los años de la ilusión de masas: la Argentina, de Yrigoyen a Perón (1930-1955). Montevidéu: Universidad de La República, 1997.

BOOTH, Douglas. Australian beach cultures: the history of sun, sand and surf. London: Frank Cass, 2001.

CHARNEY, Leo; SCHWARTZ, Vanessa. (Org.). O cinema e a invenção da vida moderna. São Paulo: Cosac e Naify, 2001.

DIGIANO, Roberto. Peronismo y fútbol: el triunfo sobre Inglaterra en 1953.

Lecturas: Educación Física y Deportes, Buenos Aires, n. 17, s.p., 1999. 
JAKUBOWICZ, Eduardo; RADETICH, Laura. La historia argentina a través del cine. Buenos Aires: La Crujía, 2006.

LUNA, Félix. Perón y su tiempo: II. La comunidad organizada 1950-1952. Buenos Aires: Editorial Sudamericana, 2000.

LUPO, Victor. Historia política del deporte argentino (1610-2002). Buenos Aires: Corregidor, 2004.

MANRUPE, Raul; PORTELA, Maria Alejandra. Un diccionário de films argentinos. Buenos Aires: Corregidor, 1995.

MARANGHELLO, César. Breve história del cine argentino. Barcelona: Laertes, 2005.

MARAÑON, Carlos. Futbol y cine. Madrid: Ocho y Medio, 2005.

MELO, Victor Andrade de; FORTES, Rafael. O surfe no cinema e a sociedade brasileira na transição dos anos 1970/1980. Rio de Janeiro: 2008. mimeo.

MELO, Victor Andrade de; VAZ, Alexandre Fernandes. Cinema, corpo, boxe: suas relações e a construção da masculinidade. Artcultura, Uberlândia, v. 8, n. 12, p. 139-160, 2006.

MELO, Victor Andrade de. Futebol e cinema: relações. Revista Portuguesa de Ciências do Desporto, Porto, v. 6, n. 3, p. 362-270, out.-dez. 2006b.

MELO, Victor Andrade de. O esporte no cinema de Portugal. Revista Portuguesa de Ciências do Desporto, Porto, v. 8, n. 1, p. 157-168, jan.-abr. 2008.

MELO, Victor Andrade de. Cinema e esporte: diálogos. Rio de Janeiro: Aeroplano, 2006a.

MERIDA, Pablo. El boxeo en el cine. Barcelona: Kaplan, 1995.

RAMIÓ, Joaquim Romaguera. Presencia del deporte em el cine español. Madrid: Fundación Andalucia Olímpica y Consejo Superior de Deportes, 2003.

REIN, Raanan. "El Primer Deportista": the political use and abuse of sport in peronist Argentina. The International Journal of the History of Sport, v. 15, n. 2, p. 54-76, 1998.

SURRA, Roberto. Peronismo y cultura. Buenos Aires: Corregidor, 2003. 